\title{
CONFLITO PELO USO DA ÁGUA NA BACIA HIDROGRÁFICA DO RIO SÃO MARCOS: O ESTUDO DE CASO DA UHE BATALHA
}

\author{
Lívia Maria da Costa Silva ${ }^{1}$ \\ Mônica de Aquino Galeano Massera da Hora ${ }^{2}$
}

\begin{abstract}
Resumo: No Brasil, a Lei $n^{\circ}$ 9.433/97 determinou que a gestão da água deve promover os seus múltiplos usos de forma descentralizada e com a participação das partes envolvidas. Esta lei visou incorporar modernos princípios de gestão e instrumentos para o sistema brasileiro de gestão dos recursos hídricos. Em algumas áreas, com escassez sazonal e com má distribuição espacial, o acesso à água e a garantia de seus múltiplos usos têm gerado conflitos. Diversos conflitos pelo uso da água são descritos na literatura, no entanto, no que tange ao setor hidrelétrico e a agricultura, não há referências de problemas solucionados e bem geridos. Neste contexto, destaca-se o atual conflito pelo uso da água na bacia do rio São Marcos entre os irrigantes e a UHE Batalha. A região está sob a jurisdição de diversos órgãos gestores e comitês de bacia. De acordo com os cenários para simulação da geração de energia em função dos usos crescentes de água, os resultados mostraram perdas energéticas variando entre $8,0 \%$ e $19,7 \%$, para energia média. $\mathrm{Na}$ busca por dirimir o conflito, a médio prazo, é necessário que as partes envolvidas discutam, a fim de poder utilizar da melhor forma a flexibilização das outorgas e a energia assegurada.
\end{abstract}

Palavras-chave: geração hidrelétrica; UHE Batalha; irrigação; gestão de recursos hídricos.

Abstract: In Brazil, Act number 9.433/97 defines the water resources management and multiple uses in a decentralized way with the participation of all involved stakeholders. This law aims to incorporate the updated water resources management principles and means into the Brazilian Water Resources Management System. Finite natural resource featured by a seasonal shortage, in some areas, and with an irregular spatial distribution, water uses can led to conflict. The multiple conflicts caused by water uses are described in the literature, but the conflict between hydropower generation and irrigation is an example that there are no references of solution and management success. In this context the current conflict in the São Marcos river basin among farmers and the Batalha hydropower plant became a difficult problem to solve. The region is simultaneously managed by various agencies and by the Watershed Committee. According to the scenarios for power generation simulation as a function of increasing of water use, energy losses results showed varying between $8.0 \%$ and $19.7 \%$ for average energy. In attempting to solve the conflict on a medium-term, it is necessary that the stakeholders discuss this subject deeply making the best use of the water grants and of the assured energy.

Keywords: hydropower generation; UHE Batalha; irrigation; water resources management.

\footnotetext{
${ }^{1}$ Departamento de Engenharia Agrícola e do Meio Ambiente - Universidade Federal Fluminense. Email: liviamariasilva@vm.uff.br

${ }^{2}$ Departamento de Engenharia Agrícola e do Meio Ambiente - Universidade Federal Fluminense. Email: dahora@vm.uff.br
} 


\section{INTRODUÇÃO}

Em todo mundo, a água é utilizada em diversas finalidades, como o abastecimento humano, a irrigação, a geração de energia, a navegação e a aquicultura (ANA, 2012). $E$, na medida em que os países se desenvolvem, aumenta a demanda desse recurso, gerando um cenário de escassez e degradação hídrica. Esse fato somado a distribuição irregular da água no tempo e no espaço, gera conflitos de gestão, tanto dentro dos próprios países, quanto entre nações, quando, por exemplo, há rios fronteiriços e transfronteiriços (Wolf et al., 1999; Calhman, 2008).

$\mathrm{Na}$ atualidade, há um entendimento, cada vez maior, de que a crise de água existente é mais uma questão de gestão inadequada dos recursos hídricos do que de escassez hídrica. A governança da água abrange uma gama de sistemas políticos, sociais, econômicos e administrativos, desenvolvidos para alocação e gestão de recursos hídricos e para implementação de soluções para melhoria da qualidade da água. Ademais, o termo governança engloba "os mecanismos, processos $\mathrm{e}$ instituições, por meio dos quais todas as partes interessadas, inclusive cidadãos e grupos de interesse, articulam suas prioridades, exercem seus direitos legais, cumprem suas obrigações e mediam suas diferenças" (UNDP-WGF, 2012). Assim, a governança da água inclui, em particular, acordos internacionais e a legislação nacional; a implementação de políticas e as instituições associadas (monitoramento e aplicação de normas); e a participação da sociedade civil e do setor privado, stakeholder involvement.

No Brasil, a Lei $n^{\circ}$ 9.433/97, também conhecida por Lei das Águas, buscou ser uma inovação na gestão, no ordenamento e no planejamento do uso da água nas bacias hidrográficas. No entanto, ao longo dos anos, têm sido observados diversos conflitos de gestão (Almeida et al., 2007; Gondim, 2009; Abbink et al., 2010), no que tange os diversos usos, principalmente, entre o setor elétrico (hidroeletricidade), a navegação, os usos consuntivos $\mathrm{e}$ as restrições à operação tanto a montante como a jusante do barramento das usinas (Mdemu \& Magayane, 2005). Como o sistema elétrico brasileiro é extremamente concentrado na fonte de origem hídrica, mais de $90 \%$, surge um sério impasse de difícil solução de gerenciamento: como atender a todos os usos em uma bacia hidrográfica com escassez hídrica quantitativa ou qualitativa?

Neste contexto, o objetivo principal do presente trabalho residiu em analisar o conflito pelo uso da água entre a atual e futura demanda da irrigação, em especial, por meio de pivôs centrais, e o aproveitamento hidrelétrico da UHE Batalha, localizada na bacia hidrográfica do rio São Marcos. Além disso, buscou-se avaliar a questão das possíveis perdas de energia produzida, associadas aos usos consuntivos crescentes a montante da UHE Batalha.

\section{METODOLOGIA}

\subsection{REGIÃO DE ESTUDO: BACIA HIDROGRÁFICA DO RIO SÃO MARCOS}

Após o rio Paranaíba tornar-se limítrofe estadual, entre Goiás e Minas Gerais, ele recebe o rio São Marcos, um dos principais tributários da margem direita. O São Marcos é um dos quatro rios de esfera federal da bacia hidrográfica do rio Paranaíba, sendo formado a partir do córrego Samambaia, que nasce a uma altitude de cerca de $1.000 \mathrm{~m}$, em território do Distrito Federal. Desde sua nascente, até o encontro com o rio Paranaíba, percorre uma distância de cerca de 480 $\mathrm{km}$.

A bacia hidrográfica do rio São Marcos localiza-se na região Central do Brasil, entre os paralelos $16^{\circ}$ e $18^{\circ}$ de latitude sul, e os meridianos $47^{\circ}$ e $48^{\circ}$ de longitude Oeste, abrangendo, além de parte do Distrito Federal, as terras dos Estados de Goiás e Minas Gerais, com área de 11.950 $\mathrm{km} 2$ (COBRAPE, 2011). A bacia tem por afluentes, pela margem esquerda, os ribeirões Soberbo, Mundo Novo e da Batalha e o rio São Bento, e pela margem direita, o rio Samambaia e os ribeirões 
Arrojado, São Firmino, Castelhano e Imburu. Os municípios pertencentes a essa bacia são: Catalão, Cristalina, Ouvidor, Campo Alegre de Goiás, Ipameri, Davinópolis, Três Ranchos, Paracatu, Unaí e Guarda-Mor, sendo os três últimos inseridos no Estado de Minas Gerais. Como ilustrado na Figura 1, no local da UHE Batalha, o rio São Marcos divide os Estados no limite entre os municípios de Paracatu e Cristalina, respectivamente (COBRAPE, 2011).

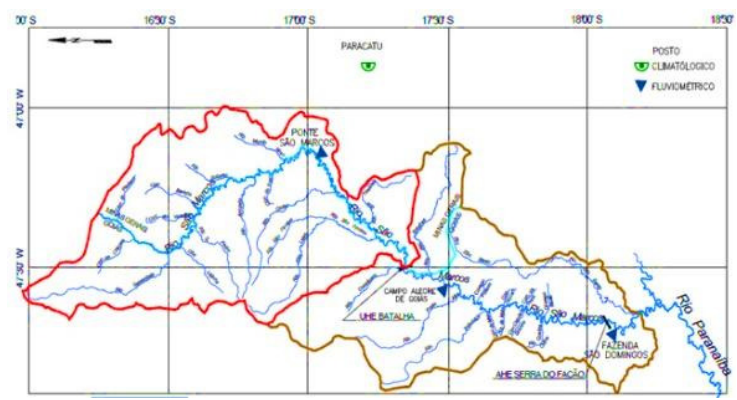

Figura 1 - Mapa da região da bacia hidrográfica do rio São Marcos, mostrando a localização da UHE Batalha (FURNAS, 2006).

Quanto à ocupação do solo, trata-se de uma região com grande produção agrícola com a utilização de técnicas modernas de pivôs de irrigação. A situação atual é consequência do processo de modernização da agricultura nas áreas do Cerrado brasileiro que se intensificou principalmente na década de 90 , quando se desencadeou a expulsão do homem do campo para a cidade, promovendo a concentração fundiária (Florêncio et al., 2009). Nas partes mais altas da bacia, municípios de Cristalina/GO, Unaí/MG e Paracatu/MG, onde ocorre a formação de chapadões e vales abertos e suaves, são expressivas as atividades econômicas voltadas a produção agropecuária.

Em relação aos estudos hídricos da região mostrados no Plano de Recursos Hídricos da bacia hidrográfica do rio Paranaíba, PRH-Paranaíba, algumas regiões da bacia do rio São Marcos possuem balanço hídrico, relação entre demanda e disponibilidade, deficitário. E, além disso, o PRH-Paranaíba relata conflitos, dentre eles, o conflito entre o aproveitamento hidrelétrico da UHE Batalha e a atual demanda (e futura) da irrigação, em especial, por meio de pivôs centrais (COBRAPE, 2011; Collischonn, 2011).

\section{$3 . \quad$ LEVANTAMENTO DAS INFORMAÇÕES}

A metodologia utilizada no presente trabalho foi baseada, primeiramente, em uma pesquisa bibliográfica e documental que levou a seleção crítica do arcabouço teórico relacionado ao tema. Posteriormente, houve o levantamento dos dados qualitativos e quantitativos, principalmente, no PRH-Paranaíba e nas notas técnicas e resoluções da Agência Nacional de Águas (ANA). Com bases nas informações, o trabalho foi desenvolvido, analisando-se, de forma crítica, o estudo de caso.

\section{SIMULAÇÃO DA GERAÇÃO DE ENERGIA HIDRELÉTRICA}

Os dados sobre a UHE Batalha foram extraídos do projeto básico da usina (FURNAS, 2006) e do Sistema de Informações do Potencial Hidrelétrico Brasileiro - SIPOT, desenvolvido pela Eletrobras.

Para a avaliação da geração de energia pela UHE Batalha e a sua compatibilização com os usos crescentes da água, foi utilizada a ferramenta computacional SisUCA - Sistema de Simulação de Usinas com Usos Consuntivos da Água, desenvolvida por HORA (2012). Basicamente, o modelo adota a formulação matemática desenvolvida no modelo MSUI - Modelo de Simulação a Usinas Individualizadas, desenvolvido pela Eletrobras. A inovação da formulação decorre da introdução de uma nova variável representada por retiradas de água, limitada a totalidade da vazão máxima outorgável - VMO. No que diz respeito à operação, a usina hidrelétrica é representada pela equação do balanço hídrico:

$$
\begin{aligned}
& \Delta \mathrm{V}_{\mathrm{i}}=\left[\mathrm{Qaflu}_{\mathrm{i}}-\text { Qturb }_{\mathrm{i}}-\text { Qvert }_{\mathrm{i}}-\text { Qevap }_{\mathrm{i}}\right] \cdot \mathrm{ns} \\
& \mathrm{Qaflu}_{\mathrm{i}}=\left[\text { Qincr }_{\mathrm{i}}+\sum_{\mathrm{k}=1}^{\mathrm{n}} \mathrm{Qdefl}_{\mathrm{k}}\right]-\text { Qusos } \\
& \text { Qusos } \leq \text { VMO (3) }
\end{aligned}
$$

onde: 
$\Delta \mathrm{V}_{\mathrm{i}}$ : variação de volume da usina $\mathrm{i}, \mathrm{em} \mathrm{m}^{3}$; Qaflü : vazão natural afluente à usina $\mathrm{i}$, em $\mathrm{m}^{3} / \mathrm{s}$;

Qturḅ: vazão turbinada na usina i, em $\mathrm{m}^{3} / \mathrm{s}$; Qverț: vazão vertida na usina $i, \mathrm{em} \mathrm{m}^{3} / \mathrm{s}$;

Qevap : vazão evaporada do reservatório da usina i, em m³

ns: número de segundos em um mês médio;

Qinç̣: vazão incremental correspondente ao trecho entre a usina i e a(s) usina(s) $\mathrm{k}$ de montante, em m³/s;

Qdeflu $_{\mathrm{k}}$ : vazão defluente da(s) usina(s) $\mathrm{k}$ de montante, em $\mathrm{m}^{3} / \mathrm{s}$. Corresponde ao somatório das vazões turbinadas e vertidas; Qusos: vazão de retirada no trecho entre as usinas $\mathrm{k} \mathrm{e} \mathrm{i,} \mathrm{em} \mathrm{m³/s,} \mathrm{limitada} \mathrm{ao} \mathrm{valor} \mathrm{da}$ vazão máxima outorgável (VMO). A VMO representa a parcela de $70 \% \mathrm{Q}_{95 \%}$, como estabelecido na Resolução ANA $n^{\circ}$ $542 / 2004$.

As vazões naturais da UHE Batalha foram extraídas da Resolução ANA n 489/2008, para o período de 1931 a 2005. A partir dessa série, foi estimada a vazão de referência $\left(\mathrm{Q}_{95 \%}\right)$ e, em seguida, calculada a VMO.

A vazão evaporada depende da evaporação líquida do reservatório e da área do espelho d'água. Os dados de evaporação líquida foram obtidos através da utilização da ferramenta computacional SisVazNat Sistema de Reconstituição de Séries de Vazões Naturais (Hora et al., 2010), a partir dos modelos CRLE Complementary Relationship Lake e CRAE - Complementary Relationship Areal Evapotranspiration, consubstanciados em MORTON (1983 apud Hora, 2012). Na operação do setor elétrico, a produção de energia, ou ainda, o turbinamento das vazões afluentes deve buscar atender a demanda do mercado consumidor, ao custo de geração e, se possível, à ordem de prioridade da operação de esvaziamento e reenchimento da cascata (Hora, 2012). Porém, como a simulação do SisUCA prioriza a disponibilidade hídrica dos usuários de jusante, o turbinamento passa a ser regido pelas seguintes regras:
- Se o nível do reservatório no mês anterior estiver entre o mínimo normal e o máximo normal, o reservatório está em fase de enchimento ou deplecionamento, então a vazão turbinada será igual a vazão regularizada;

- Se o nível do reservatório no mês anterior estiver entre o máximo normal e o máximo maximorum, o reservatório encontra-se cheio, então a vazão turbinada será igual a vazão de engolimento máximo (Qturb $\left.{ }_{\text {máx }}\right)$. A vazão máxima turbinável pode ser estimada a partir de:

$$
\text { Qturb }_{\text {máx }}=\frac{\text { PI } \cdot 1000}{9,81 \cdot \eta_{\mathrm{i}} \cdot \mathrm{h}_{\text {ref }_{\mathrm{i}}}}
$$

onde:

PI : potência instalada na usina i, em MW; $\mathrm{h}_{\text {ref }}$ : queda de referência da usina i, em m; $\eta_{\mathrm{i}}$ : rendimento do conjunto turbinagerador-transformador da usina $\mathrm{i}$.

Segundo HORA (2012), a vazão regularizada representa a média das vazões afluentes do período em que o reservatório estava totalmente cheio (100\%), passou pelo instante em que ficou vazio $(0 \%)$, e tornou a ficar cheio novamente (100\%), sem reenchimentos totais intermediários, utilizando, neste intervalo de tempo, todo o volume útil do reservatório.

\section{RESULTADOS E DISCUSSÃO}

\subsection{CONFLITO PELO USO DA ÁGUA NA BACIA HIDROGRÁFICA DO RIO SÃO MARCOS}
A
Nota
Técnica
$\mathrm{n}^{\mathrm{o}}$
111/2007/GEREG/SOF-ANA trata dos primeiros estudos desenvolvidos pela ANA para o levantamento dos irrigantes por pivôs centrais e dos pontos de barramento. No documento, foram quantificados 652 pontos de barramento e 714 pivôs, sendo que os últimos totalizavam uma área de 61.635 ha, representando $5,15 \%$ da área total da bacia.
Posteriormente, a Nota Técnica $\mathrm{n}^{\circ}$ 023/2010/GEREG/SOF-ANA indicou a 
existência de 675 pivôs centrais na bacia a montante da UHE Batalha, totalizando uma área de 57.562 ha. $\mathrm{O}$ uso da água para irrigação por pivô central foi constatada como predominante na região.

As análises de distribuição dos pivôs nos rios estaduais e no rio São Marcos, que é federal, são relacionadas na Tabela 1, transcrita da Nota Técnica $\mathrm{n}^{\circ}$ 023/2010/GEREG/SOF-ANA. Os dados mostraram que a maioria da área irrigada encontra-se em rios estaduais, sendo boa parte em reservatórios particulares. Além disso, a área irrigada total estimada de 57.562 ha representava $9 \%$ da cobertura da bacia.

Tabela 1 - Área irrigada estimada e outorgada na bacia do rio São Marcos.

\begin{tabular}{cccc}
\hline Domínio & $\begin{array}{c}\mathbf{N}^{\mathbf{0}} \mathbf{d e} \\
\text { pivôs }\end{array}$ & $\begin{array}{c}\text { Área } \\
\text { (ha) }\end{array}$ & $\begin{array}{c}\text { Percentual } \\
\text { do total }\end{array}$ \\
\hline $\begin{array}{c}\text { Federal } \\
\text { (ANA) }\end{array}$ & 99 & 7.893 & 14 \\
\hline $\begin{array}{c}\text { Estadual } \\
\text { (GO) }\end{array}$ & 302 & 25.813 & 44 \\
\hline $\begin{array}{c}\text { Estadual } \\
\text { (MG) }\end{array}$ & 274 & 23.856 & 41 \\
\hline Total & 675 & 57.562 & 100 \\
\hline
\end{tabular}

Dentre as conclusões apontadas nesta Nota Técnica, foi recomendada cautela quando da projeção de áreas irrigadas em regiões de fronteira agrícola. E, tais projeções, são necessárias na análise de pedidos de declaração de reserva de disponibilidade hídrica (DRDH), notadamente na alocação de usos consuntivos a montante dos aproveitamentos hidrelétricos. Por este motivo, a ANA sugeriu a adoção de um limiar de $10 \%$ no crescimento da área irrigada na bacia hidrográfica do rio São Marcos.

Em julho de 2010, durante a elaboração do PRH-Paranaíba, a ANA identificou um conflito pelo uso da água já instalado de grande relevância: o setor elétrico por intermédio das usinas hidrelétricas e os irrigantes para a produção de sementes, grãos e atividades de olericulturas - a maioria deles sem outorga de uso da água. Agravando a situação, na mesma época, o governo goiano, através da sua Secretaria de Estado de Gestão e Planejamento, negociou um financiamento com $\mathrm{O}$
Ministério da Integração para a implantação de infraestrutura hídrica de apoio à irrigação na bacia.

A ANA publicou em agosto de 2010, a Nota Técnica $n^{\circ}$ 104/2010/GEREG/SOFANA que foi elaborada com o objetivo de fornecer subsídios ao Marco Regulatório na bacia do rio São Marcos. O documento apontou a existência de 666 pivôs centrais na bacia a montante da UHE Batalha, totalizando uma área de 56.763 ha. Ademais, os pedidos de outorga para agricultura de pivô central, existentes na ANA, davam conta de uma vazão específica captada média de $0,15 \mathrm{~L} / \mathrm{s} / \mathrm{ha}$ ao longo do ano, estimando-se um consumo anual de água, a montante da UHE Batalha, da ordem de $7,59 \mathrm{~m}^{3} / \mathrm{s}$. O valor encontrado foi bem superior ao consumo médio estimado, para o horizonte de 2010, previsto na Resolução ANA $n^{\circ}$ 364/2005, que trata da DRDH da UHE Batalha, que foi de $1,62 \mathrm{~m}^{3} / \mathrm{s}$.

Posteriormente, através da Superintendência de Regulação, a ANA emitiu o Marco Regulatório de uso da água na bacia do rio São Marcos, por meio da Resolução ANA $n^{\circ}$ 562/2010. O documento foi motivado devido à "vocação da bacia do rio São Marcos para agricultura irrigada" e ao "potencial de crescimento deste uso da água; considerando a necessidade de compatibilização entre os usos de irrigação e energia elétrica na bacia do São Marcos". A área de abrangência do Marco Regulatório foi definida pela bacia do rio São Marcos a montante da UHE Batalha. A vazão média anual consumida na bacia, a montante da UHE Batalha, seria de, no máximo, $8,7 \mathrm{~m}^{3} / \mathrm{s}$, sem menção de horizonte, de forma a respeitar os limites previstos para a outorga da usina e a legislação referente ao setor elétrico. Devido ao Marco Regulatório, a ANA, por meio da Resolução ANA no 564/2010, alterou as vazões de usos consuntivos a serem subtraídas das vazões naturais médias mensais afluentes à UHE Batalha.

Infelizmente, apesar dos órgãos gestores de recursos hídricos dos Estados de Goiás, representados pela Secretaria do Meio Ambiente e dos Recursos Hídricos de Goiás - SEMARH/GO, e Minas Gerais, 
representados Instituto Mineiro de Gestão das Águas - IGAM, terem participado do processo de elaboração do Marco Regulatório, não o replicaram em seus territórios, conforme acordado e não implementaram ações de controle e fiscalização, a fïm de regularizar a situação dos seus usuários irrigantes (Silva, 2012).

Finalmente, diante do conflito estabelecido pelo crescimento da demanda hídrica para irrigação a montante da UHE Batalha, em fevereiro de 2012, a ANA interveio e promoveu o debate entre os interessados, através da formação de um Grupo Técnico, visando buscar uma solução para o conflito e garantir a disponibilidade hídrica e o equilíbrio ambiental da região. Entretanto, nem todas as concessionárias das usinas hidrelétricas a jusante de Batalha, que também são afetadas, foram convidadas a participar da discussão (Silva, 2012).

\subsection{OS IRRIGANTES}

Segundo AQUINO (2012), o Vale do Pamplona, que engloba parte do Distrito Federal e partes de algumas cidades de Goiás, como Luziânia e Cristalina, é uma região que apresenta mais de 250 rios, riachos e ribeirões, além dos rios Pamplona, São Marcos e São Bartolomeu. A região tem o título de maior área irrigada da América Latina, de acordo com informações da Secretaria Municipal da Integração e Agrodefesa de Cristalina. Segundo AQUINO (2012), os principais argumentos dos irrigantes para a legitimidade da sua expansão são: a produção de alimentos no país; as condições muito favoráveis para a expansão da agricultura na região do planalto central do Brasil e a expansão da fronteira agrícola.

Outro ponto que favorece o lado dos irrigantes é o fato da Câmara dos Deputados ter aprovado, em 27 de junho de 2012, a proposta que institui a nova Política Nacional de Irrigação para o País, Projeto de Lei $\mathrm{n}^{\circ} 6.381 / 2005$. A política tem como objetivo incentivar a ampliação da área irrigada e aumentar a produtividade agrícola. Entre os incentivos criados está a ampliação dos descontos nas tarifas de energia elétrica cobradas em atividades de irrigação. A proposta também cria o Sistema Nacional de Informações sobre Irrigação e objetiva o uso racional dos recursos hídricos.

Finalmente, vale lembrar que, apesar dos argumentos dos irrigantes serem válidos, a maioria dos agricultores não possui outorga para a captação da água, utilizada na irrigação via, principalmente, pivô central, dos afluentes da bacia do rio São Marcos (Silva, 2012).

\subsection{A UHE BATALHA}

Para o desenvolvimento e implantação de empreendimentos de geração hidrelétrica é necessário que haja o desenrolar de um processo que é estabelecido na legislação do setor de energia elétrica e que envolve uma série de investigações e estudos a serem submetidos à aprovação dos órgãos reguladores, tais como: licenças ambientais e outorga de direito de uso de recursos hídricos.

Para o empreendimento UHE Batalha, que foi inicialmente denominado de AHE Paulistas, através da Resolução ANA $n^{\circ}$ 364/2005, foi concedida a outorga preventiva de uso de recursos hídricos, com a finalidade de declarar a disponibilidade de água necessária à viabilidade do aproveitamento hidrelétrico. Após a concessão de uso do potencial de energia hidráulica por parte da Agência Nacional de Energia Elétrica - ANEEL, a DRDH se transformou automaticamente em outorga de direito de uso de recursos hídricos, Resolução ANA no 489/2008.

Em dezembro de 2005, o Instituto Brasileiro do Meio Ambiente e dos Recursos Naturais Renováveis - IBAMA emitiu a Licença Prévia $n^{\circ}$ 222/2005 evidenciando a viabilidade ambiental do aproveitamento hidrelétrico. Em seguida, em 16 de dezembro de 2005, o aproveitamento hidrelétrico foi arrematado por Eletrobras Furnas no Leilão de Energia Nova $n^{\circ} 002 / 2005$. Em 2006, através do contrato de concessão $n^{\circ}$ 002/2006-MMEUHE BATALHA, Eletrobras Furnas tornou-se concessionária da UHE Batalha. Em 2008, a Licença de Instalação $\mathrm{n}^{\circ}$ 499/2008 foi emitida pelo IBAMA. 
A UHE Batalha teve sua construção iniciada, em meados de 2008, com previsão de potência instalada de 52,5 MW. A barragem, de $50 \mathrm{~m}$ de altura, está situada no Estado de Goiás, na divisa dos municípios de Cristalina (GO) e Paracatu (MG). Segundo o ONS (2013), o enchimento atingiu a sua cota mínima operacional $(785 \mathrm{~m})$ no dia 19 de janeiro de 2013.

No entanto, o Marco Regulatório gerou a necessidade de modificação do Anexo II vazões referentes aos usos consuntivos da Resolução ANA nº 489/2008, editando-se a Resolução ANA n ${ }^{\circ}$ 564/2010, como mostrado na Tabela 3. Em virtude dos novos valores de vazão disponíveis para usos consuntivos, segundo a Nota Técnica $\mathrm{n}^{\mathrm{o}} \quad 104 / 2010 /$ GEREG/SOF-ANA foi estimada uma redução de $5 \%$ na energia assegurada pela UHE Batalha. O cálculo da energia assegurada foi baseado na energia gerada no período crítico do sistema elétrico brasileiro.

Tabela 3 - Vazões dos usos consuntivos a montante da UHE Batalha, no período de 2010 a 2040.

\begin{tabular}{c|ccccccc}
\hline \multirow{2}{*}{ Res. } & \multicolumn{7}{|c}{ Ano/Vazões $\left(\mathbf{m}^{3} / \mathbf{s}\right.$ ) } \\
\cline { 2 - 7 } ANA & $\mathbf{2 0}$ & $\mathbf{2 0}$ & $\mathbf{2 0}$ & $\mathbf{2 0}$ & $\mathbf{2 0}$ & $\mathbf{2 0}$ & $\mathbf{2 0}$ \\
& $\mathbf{1 0}$ & $\mathbf{1 5}$ & $\mathbf{2 0}$ & $\mathbf{2 5}$ & $\mathbf{3 0}$ & $\mathbf{3 5}$ & $\mathbf{4 0}$ \\
\hline $\mathbf{4 8 9 / 2}$ & 1,6 & 2,0 & 2,6 & 3,4 & 4,5 & 5,8 & 7,6 \\
$\mathbf{0 0 8}$ & 2 & 8 & 9 & 9 & 3 & 9 & 7 \\
\hline $\mathbf{5 6 2 / 2}$ & \multicolumn{7}{|c}{8,70 (valor máximo) } \\
$\mathbf{0 1 0}$ & \multicolumn{7}{|c}{} \\
\hline $\mathbf{5 6 4 / 2}$ & 7,5 & 8,6 & 9,6 & 10, & 11, & 12, & 13, \\
$\mathbf{0 1 0}$ & 9 & 3 & 2 & 62 & 62 & 62 & 61 \\
\hline
\end{tabular}

\subsection{SIMULAÇÃO DA GERAÇÃO DE ENERGIA}

As simulações da operação hidráulica energética da UHE Batalha, a partir do uso da ferramenta computacional SisUCA, foram efetuadas considerando em um primeiro cenário a ausência de retirada de vazões e nos seguintes retiradas crescentes de parcelas representadas por $40 \%, 50 \%$, $65 \%$ e $100 \%$ da VMO (igual a $20,86 \mathrm{~m}^{3} / \mathrm{s}$ ). Os percentuais de $40 \%\left(8,34 \mathrm{~m}^{3} / \mathrm{s}\right)$ e $65 \%$ $\left(13,56 \mathrm{~m}^{3} / \mathrm{s}\right)$ foram escolhidos por representarem, aproximadamente, os valores do Marco Regulatório e da Resolução ANA $n^{\circ}$ 564/2010, como ilustrado na Tabela 3. Os valores resultantes de geração são mostrados na Figura 2. A energia média foi resultante da simulação do período de janeiro de 1931 a dezembro de 2005 . No que tange a energia firme, essa foi resultante da simulação do período crítico do sistema elétrico brasileiro (junho de 1949 a novembro de 1956).

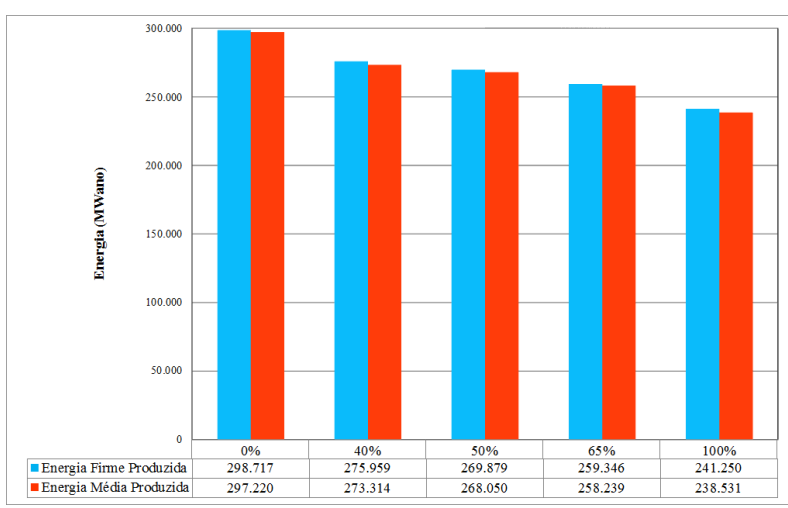

Figura 2 - Produção das energias média e firme no atendimento às demandas crescentes de água para usos consuntivos.

Como era de se esperar, o atendimento crescente de vazões para os demais usos a montante do reservatório da UHE Batalha implica na redução da produção de energia. Cabe destacar que os valores de energia firme encontrados foram um pouco superiores aos de energia média, indicando que o período crítico da bacia não coincide com o período crítico do sistema, como pode se constatar ao se analisar a série de vazões naturais da Resolução ANA $n^{\circ}$ 489/2008, na qual o menor valor corresponde a outubro de 1971. As Figuras 3 e 4 mostram a geração de energia média e energia firme e as perdas energéticas associadas aos usos consuntivos crescentes de água, respectivamente.

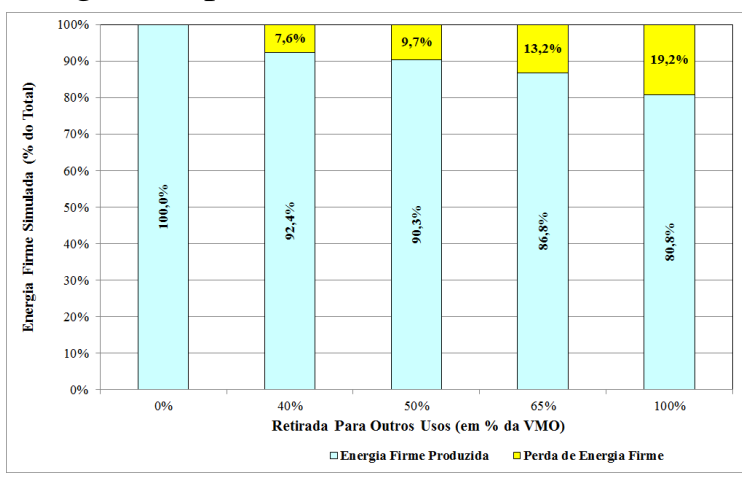

Figura 3 - Perdas globais de energia firme. 


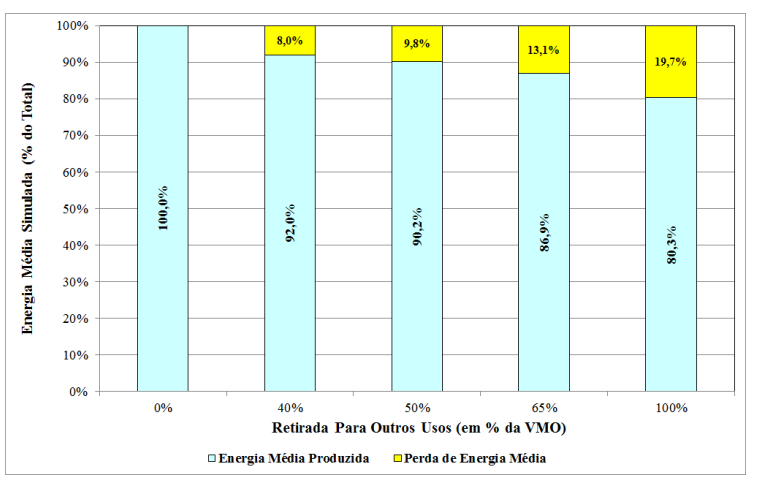

Figura 4 - Perdas globais de energia média.

Apesar da Nota Técnica $n^{\circ}$ 104/2010/GEREG/SOF-ANA relatar que haveria uma redução de $5 \%$ da energia assegurada ou firme, as simulações realizadas no presente estudo, mostraram que as perdas podem ser maiores. Se for considerado o horizonte do ano 2040 da Resolução ANA $n^{\circ}$ 564/2010, o qual define a vazão de 13,61 $\mathrm{m}^{3} / \mathrm{s}$, aproximadamente $65 \%$ da VMO que é de $13,56 \mathrm{~m}^{3} / \mathrm{s}$, as perdas energéticas poderão se situar em $13,1 \%$ para a energia média e em $13,2 \%$ para a energia firme. Para o pior cenário de retirada de água, $100 \%$ da VMO, as perdas energéticas poderão se situar em 19,7\% para a energia média e $19,2 \%$ para a energia firme.

\section{CONCLUSÕES}

A falta de uma estratégia de gestão da água, no Brasil, ameaça agravar os conflitos provocados pela escassez de recursos hídricos. Os conflitos gerados pelos diversos usos já foram observados em diversas regiões, dentre elas, o semiárido nordestino. O conflito pelo uso da água entre o setor agrícola, irrigantes, e o setor de geração de energia, hidrelétricas, é recente, visto que não há referências de soluções que pudessem servir de exemplos como já resolvidos e bem geridos. Assim, desde 2010, a bacia hidrográfica do rio São Marcos tem sido uma região de grande preocupação devido ao conflito instalado e ainda sem solução.

Trata-se de um caso de extrema complexidade da gestão dos recursos hídricos pelo fato de estar vinculada a quatro órgãos gestores de recursos hídricos; três comitês de bacia, Paranaíba, Lago Paranoá e Comitê Estadual dos Rios Corumbá, Veríssimo e São Marcos; além de quatro conselhos de recursos hídricos, Conselho Nacional de Recursos Hídricos, Conselho Estadual de Recursos Hídricos de Minas Gerais, Conselho Estadual de Recursos Hídricos de Goiás e Conselho de Recursos Hídricos do Distrito Federal.

Por último, cabe destacar que já se constata que uma parte significativa da bacia a montante da UHE Batalha apresenta déficit hídrico que se reflete em um conflito entre os setores agrícola e de geração de energia. Isto implicou na edição de inúmeras resoluções pela ANA na tentativa de disciplinar o uso da água na região. As vazões definidas pela ANA para os usos consuntivos a montante da UHE Batalha foram modificadas de $1,62 \mathrm{~m}^{3} / \mathrm{s}$ para $8,70 \mathrm{~m}^{3} / \mathrm{s}$ e, finalmente para 13,61 $\mathrm{m}^{3} / \mathrm{s}$, ao longo do tempo. Os dois últimos valores representam, respectivamente, $40 \%$ e $60 \%$ da VMO. De acordo com os cenários para simulação da geração de energia em função dos usos crescentes de água, os resultados mostraram perdas energéticas variando entre $8,0 \%$ e $19,7 \%$, para energia média, e entre $7,6 \%$ e $19,2 \%$, para energia firme.

\section{REFERÊNCIAS}

ABBINK, K., MOLLER, L.C., O'HARA, S. 2010. Sources of Mistrust: An Experimental Case Study of a Central Asian Water Conflict. Environmental and Resource Economics Journal, v.45, p.283318.

ALMEIDA, R.A., VIANA, A.N.C., ALVEZ, A.S.V. 2007. Impacto do deplecionamento de reservatórios de regularização no setor de turismo em municípios lindeiros: o caso do reservatório de Furnas. XVII Simpósio Brasileiro de Recursos Hídricos. São Paulo.

ANA. 2012. Conjuntura dos Recursos Hídricos no Brasil: informe 2012. Edição especial. Agência Nacional de Águas. Brasília. 215 p. 
AQUINO, T. Irrigação e Sustentabilidade. Produtores irrigantes de Goiás garantem que sistema não é o vilão do desperdício de água. Revista Campo, n. 205, p. 20-23, Julho 2012.

CALHMAN, O.K.B. Gestão de recursos hídricos em bacias de rios fronteiriços $e$ transfronteiriços - rio Quaraí/bacia do Prata. Rio de Janeiro. 2008. 302 p. Tese (Doutorado em Engenharia Civil). COPPE. Universidade Federal do Rio de Janeiro. Rio de Janeiro, 2008.

COBRAPE. Diagnóstico da bacia hidrográfica do rio Paranaíba. Plano de Recursos Hídricos da Bacia do rio Paranaíba. Revisão 2. Ago. 2011.

COLLISCHONN, B. Marco regulatório do uso da água na bacia do rio São Marcos. $15^{\mathrm{a}}$ Reunião CTPI/CBH Paranaíba. Maio, 2011.

FLORÊNCIO, B.A. B.; SILVA, E. M.; PIMENTEL, M.R.S.; SOUSA, P.C.; ASSUNÇÃO, W.L. Uso $d a$ águanabaciahidrográfica do rio São Marcos-Goiás/Brasil, In: $12^{\circ}$ Encuentro de Geografos de America Lantina,Uruguai, $2009 . \quad$ Disponível em: http://www.observatoriogeograficoamerica latina.org.mx/egal12/Procesosambientales/ Usoderecursos/41.pdf.

FURNAS. UHE Batalha - Projeto Básico - Memorial descritivo. Volume I. Texto PJ0606-B-R00-GR-MD-001-0. Dezembro, 2006.

GONDIM, J. Principais conflitos por usos múltiplos no Brasil. Apresentação no XVIII Simpósio Brasileiro de Recursos Hídricos. Campo Grande, Mato Grosso do Sul. 2009.

HORA, M. A. G. M. 2012. Compatibilização da geração de energia em aproveitamentos hidrelétricos com os demais usos dos recursos hídricos. Editora EDUFF. Niterói - RJ. 102p.
HORA, M. A. G. M; MARQUES, E.; HORA, A.F. 2010. SisVazNat: Sistema de Reconstituição de Séries de Vazões Naturais. Colorgraf Gráfica e Editora Ltda. Niterói, RJ, 2010, 75 p.

SILVA, L.M.C. 2012 . Conflito pelo uso da água na bacia hidrográfica do rio São Marcos. Trabalho de Conclusão de Curso (Graduação em Engenharia de Recursos Hídricos e do Meio Ambiente). Universidade Federal Fluminense, Niterói, RJ.

MDEMU, M.V.; MAGAYANE, M.D. Conflict of water use between hydropower and irrigation in Tanzania: the conundrum of sectoral policy approaches to water resources development. 24 de Agosto de $2005 . \quad$ Disponível em: $<$ http://www.tzonline.org/pdf/conflictofwa terusebetweenhydropowerandirrigationinta nzania.pdf $>$.

ONS. Acompanhamento do Enchimento do Reservatório da UHE Batalha. 23 de jan. 2013.

UNDP-WGF. United Nations Development Program Water Governance Facility at the Stockholm International Water Institute. Disponível em: $<$ http://www.watergovernance.org/>.

WOLF, A.T., NATHARIUS, J., DANIELSON, J., WARD, B., PENDER, J. International River Basins of the World. International Journal of Water Resources Development, v.15, n.4, p.387-427, 1999. 